\title{
Perancangan Video Edukasi Animasi 2 Dimensi Berbasis Motion Graphic Mengenai Bahaya Zat Adiktif untuk Remaja
}

\author{
Intan Permata Sari \\ 1) Program Studi Pendidikan Multimedia, Fakultas Kampus Cibiru, \\ Universitas Pendidikan Indonesia \\ Jl. Raya Cibiru Km. 15, Kab. Bandung, 40393 Telp. +227801840 \\ E-mail: Intanpermatasari@upi.edu
}

\begin{abstract}
ABSTRAK
Penelitian ini bertujuan merancang video animasi 2 dimensi berbasis motion graphic, sebagai salah satu media edukasi pengenalan bahaya zat adiktif yang ditujukan pada remaja. Video animasi 2 dimensi berbasis motion graphic merupakan salah satu media visual gerak (dinamis) satu arah. Penelitian ini menggunakan metode kualitatif dengan pendekatan model komunikasi SMCR dan pendekatan Health Belief Model. Semakin berkembangnya konten multimedia dan media komunikasi visual gerak (dinamis) memberikan peluang bagi peneliti untuk menyampaikan informasi kesehatan yang menarik, dinamis dan mudah dipahami dengan memanfaatkan media visual gerak berbasis animasi motion graphic. Video animasi ini bisa menjadi pengenlan informasi tentang bahaya zat adiktif, jenis-klasifikasinya, dan dampak dari zat adiktif tersebut.
\end{abstract}

Kata kunci: Animasi 2 Dimensi, Visual Gerak, Zat Adiktif, Motion Graphic, Media Komuikasi Visual, Video Edukasi

\begin{abstract}
This study aims to design 2-dimensional animated video based on graphics, as one of the educational media about the dangers of addictive substances aimed at adolescents. 2-dimensional animated video based on motion graphic is one visual medium (dynamic) one-way motion. This study uses a qualitative method with the SMCR communication model approach and the Health Belief Model approach. The growing development of multimedia content and visual communication media (dynamic) provides an opportunity for researchers to convey interesting, dynamic and easily understood health information by utilizing visual motion media based on motion graphic animation. This animated video can be an introduction to information about the dangers of addictive substances, their type-classification, and the effects of these addictive substances.
\end{abstract}

Keywords: 2-Dimensional Animation, Visual Motion, Addictive Substance, Motion Graphic, Media Communication Visual, Educational Video

\section{Pendahuluan}

\subsection{Latar Belakang}

Berdasarkan isu strategis Laporan Kinerja Dit. Pengawasan Narkotika, Psikotropika, dan Zat Adiktif (2016) bahawa Semakin banyak penggunaan produk tembakau, narkotika, psikotropika dan prekursor ilegal oleh masyarakat khususnya di kalangan remaja. Permasalahan ini selain berkaitan langsung dengan aparat hukum, juga berkaitan pada keluarga, orang lain disekitar tempat tinggal, lingkungan di sekolah, dan remaja itu sendiri. Kurangnya kesadaran dan pengetahuan akan bahayanya zat adiktif, mengakibatkan semakin banyaknya remaja menyalahgunakan penggunaan zat adiktif itu, sehingga remaja menjadi malas belajar dan tidak termotivasi untuk sukses, serta mengakibatkan remaja tersebut berhenti sekolah. Apabila hal ini terus-menerus terjadi, maka permasalahan ini akan sangat berbahaya dalam proses pembangunan nasional.

Pada laporan Direktorat Reserse Narkoba Polda Metro Jaya (2013), Pengguna narkotika, psikotropika, dan zat adiktif (napza) diperkirakan sekitar 5 juta orang atau 2,8\% dari seluruh penduduk Indonesia. Pengguna remaja yang berusia 12-21 tahun sekitar 14.000 orang dari jumlah remaja di Indonesia yang berjumlah 70 juta orang. Adapun karakteristik remaja yaitu: masih mencari identitas diri, mencoba melakukan eksperimen, melakukan kegiatan yang menantang agar memperoleh pengakuan hebat, bersifat energik, dinamis, dan mudah tergoda oleh tekanan. 
Penyalahgunaan zat adiktif berawal dari mengikuti pergaulan dan kebiasaan adiktif seperti merokok, minum minuman beralkohol \& kafein, dan mencoba untuk memenuhi rasa ingin tahu terhadap zat adiktif lainnya.

Berdasarkan permasalah diatas maka perlunya upaya menyadarkan remaja untuk tidak menggunakan Narkoba, Alkohol, Psikotropika, dan Zat Adiktif lainnya. Pengetahuan dan pemahaman yang rinci dan terstruktur tentang bahaya zat adiktif perlu diberikan kepada remaja untuk menghindari terjerumus perilaku menyimpang. Peneliti bertujuan merancang sebuah video animasi 2 dimensi berbasis motion graphic, sebagai salah satu media edukasi untuk menyadarkan remaja terhadap bahaya zat adiktif. Video Animasi 2D berbasis Motion Graphic merupakan salah satu media audio visual yang tergolong dalam media komunikasi visual gerak/Dinamis satu arah. Berdasarkan penelitiam Lindstrom (1994) dalam munir bahwa orang dapat menerima informasi 15\% dari apa yang mereka lihat dan $30 \%$ dari apa yang mereka lihat dan dengar. Dengan adanya Video Animasi 2D berbasis Motion Graphic ini diharapkan remaja dapat mengerti dan menyadari tentang bahayanya zat adiktif.

\subsection{Zat Adiktif}

Zat adiktif merupakan zat-zat yang terkandung dalam obat-obatan. Adiktif berarti obat-obatan khusus yang dapat membuat seseorang menjadi kecanduan atau "adiksi" secara fisik maupun psikhis terhadap obat tertentu. Selain itu ada juga obat-obatan psikoaktif yang merupakan jenis obat yang dapat mempengaruhi fungsi otak dan susunan saraf seseorang, sehingga berdampak pada mood serta perilaku. Narkoba merupakan jenis obat yang termasuk obat-obatan psikoaktif, karena berdampak pada perubahan jalan pikiran dan susunan syaraf pusat seseorang. Definisi narkoba menurut WHO (1982) adalah obat yang dimasukkan kedalam tubuh baik berupa zat yang padat, cair, maupun gas yang dapat mengubah fungsi atau struktur tubuh secara fisik dan psikhis. Adapun ciri-ciri remaja yang rentan terkena narkotika, alkohol, psikotropika, rokok dan zat adiktif lainnya, yaitu (1) Perasaan galau, (2) Tekanan Lingkungan, (3) Pemberontakan, (4) Keingintahuan, (5) Jiwa petualang, (6) Meniru orang dewasa, (7) Obat mujarab, dan (8) Keyakinan yang salah.

\subsection{Animasi 2 Dimensi berbasi Motion Graphic}

Pada dasarnya animasi merupakan suatu disiplin ilmu yang memadukan unsur seni, desain dan teknologi. Teknik animasi 2D merupakan jenis animasi yang memiliki sifat flat secara visual, dengan menggunakan gambar bersumbu (axis) dua yaitu X dan Y. Animasi adalah salah satu media audio visual yang mengandung unsur hiburan, edukasi, dan berpotensi memberikan informasi yang menarik perhatian penonton sehingga dapat menghilangkan hal-hal yang, membosankan dan monoton.

Animasi terdiri dari 4 level utama yaitu (1) Motion, (2) Locomotion, (3) Interaction, dan (3) Emotion. Motion graphic menggunakan animasi level "motion" yang lebih sederhana dalam penggerakannya, yaitu lebih menekankan pada penggerakan objek dan eksplorasi komposisi. Motion graphic merupakan subset dari desain grafis karena dalam pembuatanya menggunakan prinsip-prinsip desain grafis, yaitu berorientasi pada objek dan media still image dengan format vector, data video dan audio. Illustrasi vector pada motion graphic selain berfungsi menarik perhatian penonton, juga bertujuan untuk memperjelaskan pesan informasi yang disampaikan. Selain itu penonton lebih mudah mengingat konsep dan gagasannya sehingga penonton termotivasi untuk melihat dan memahami informasi pada video. Motion graphic biasa digunakan di periklanan (TVC), opening program TV, profil perusahaan dan video klip music.

\section{Metode Penelitian}

Penelitian ini menggunakan metode deskriptif kualitatif, yaitu data yang digunakan berupa data deskriptif baik dalam bentuk verbal maupun visual, yang diadaptasikan dari metode Health Belief Model dan model komunikasi berlo (SMCR). Informasi yang disampaikan adalah pengenalan jenisklasifikasi zat adiktif dan bahaya zat adiktif. Selain itu peneliti juga mengadaptasikan tahap-tahap perancangan animasi $2 \mathrm{D}$ (pipeline animation) yang diimplementasikan pada pembuatan video motion graphic, tahap-tahap tersebuat adalah: (1) Pra produksi (pre-production), (2) Produksi (production), dan (3) Pasca produksi (post production). 


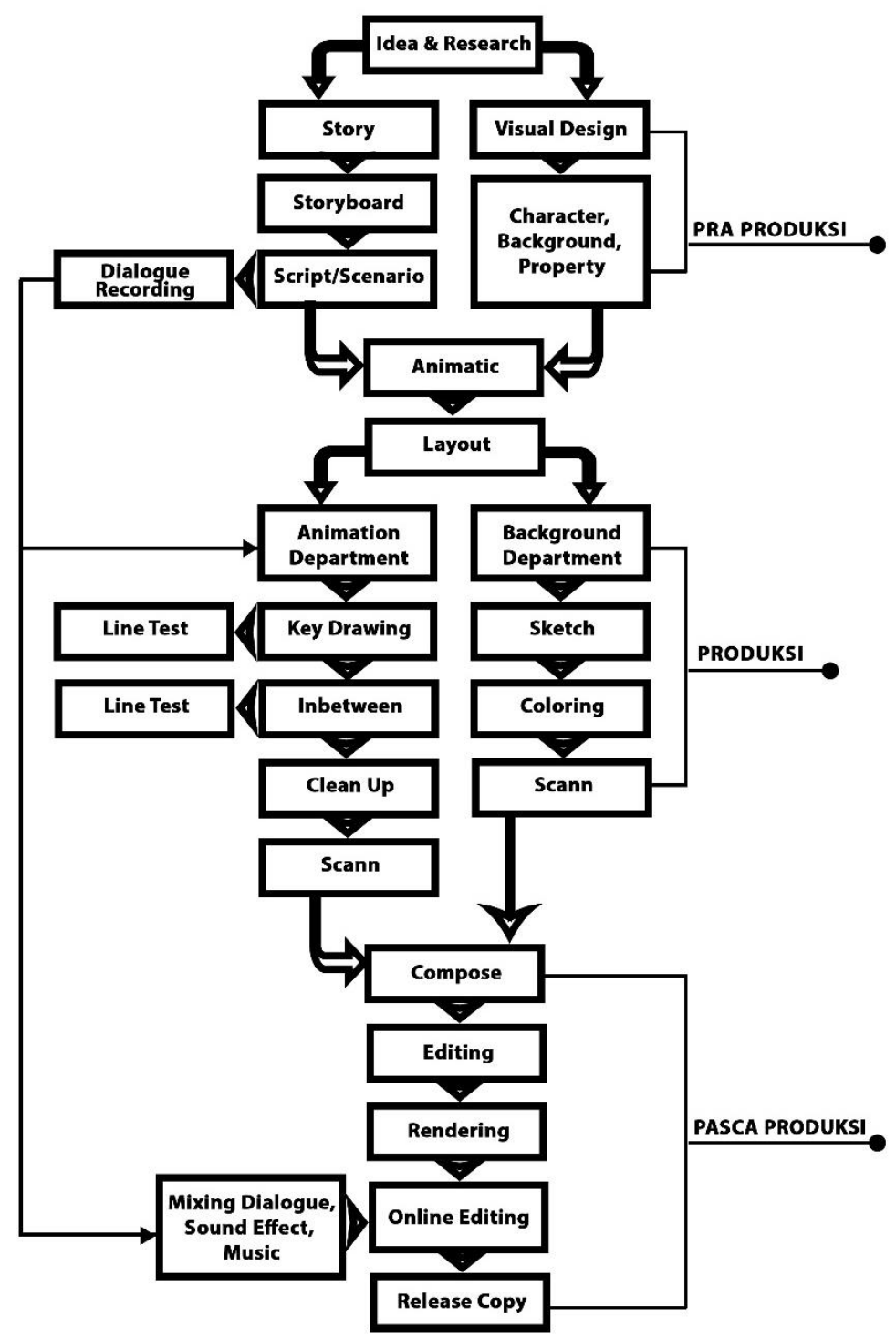

Gambar 1. Pipeline Animasi 2 Dimensi.

\subsection{Health Belief Model}

Health Belief Model merupakan teori yang biasa dipakai dalam penyuluhan kesehatan dan pendidikan sebagai bahan edukasi. Konsep Health Belief Model yang sangat mendasar adalah perilaku dan kesadaran akan kesehatan didasari dari keyakinan dan persepsi masing-masing terhadap penyakit dan cara menghindari masalah-masalah kesehatan. Health Belief Model (HBM) dapat digunakan sebagai model yang memaparkan pertimbangan sebelum seseorang berperilaku sehat. Health Belief Model (HBM) digunakan sebagai kerangka utama dalam kesehatan yang berkaitan langsung dengan manusia. Sehingga Health Belief Model (HBM) dapat digunakan sebagai pencegahan atau preventif (Green, 2014).

\subsection{Model Komunikasi SMCR}

Model SMCR oleh David K. Berlo merupakan salah satu bentuk komunikasi interaksi. SMCR merupakan singkatan dari Source, Message, Channel, dan Receiver. Source merupakan sumber penyampai pesan yang memiliki kemampuan komunikasi, sikap, pengetahuan, sistem sosial, dan budaya. Message merupakan pesan yang ada pada media tertentu. Channel merupakan media input/output pesan yang berkaitan dengan aspek inderawi, yaitu mata, telinga, hidung, mulut, dan sentuhan. Receiver merupakan penerima pesan/user yang menangkap pesan dan memberikan umpan balik. 


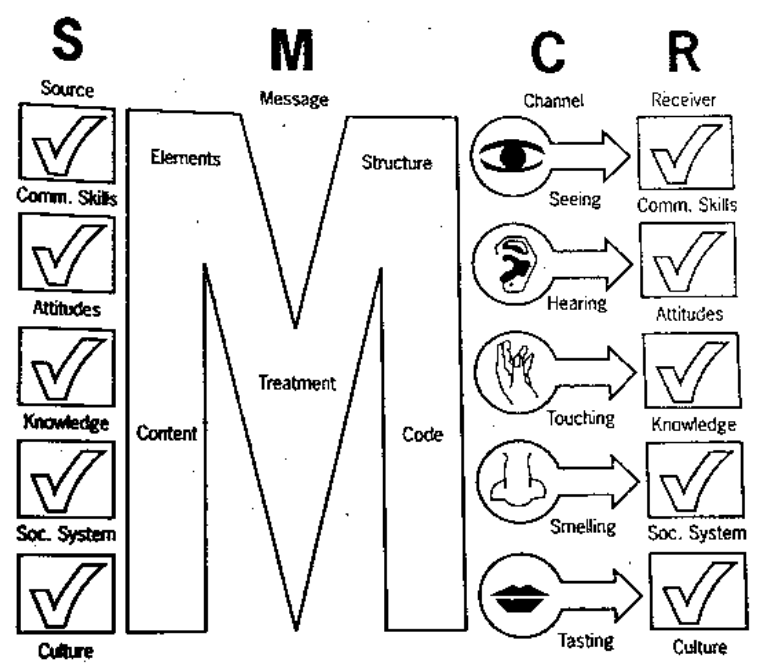

Gambar 2. Model komunikasi Berlo

\section{Hasil dan Pembahasan}

\subsection{Perancangan Video Animasi}

\section{Sinopsis}

Pada video animasi ini akan menceritakan tentang bahayanya zat adiktif. Tampilan visualisasi dimulai dari pengenalan dasar tentang zat adiktif, dampak dari pengunaan zat adiktif, klasifikasi dan jenis-jenis zat adiktif, serta contoh-contoh zat adiktif. Selain itu juga diakhir cerita ada ajakan untuk tidak menggunakan narkoba.

\section{Storyline}

Storyline dirancang berdasarkan penjabaran naskah dan diagram scene yang disusun pada tabel 1 .

\section{Warna}

Warna utama yang dipakai dalam pembuatan video animasi ini menggunakan warna abu muda (\#ced1cc), abu tua (\#565a5c), merah muda (\#ff5a5f), dan toska (\#007a87).
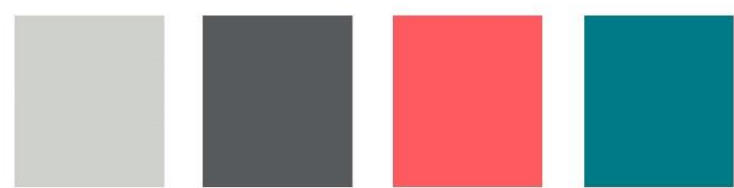

\section{\#ced1cc \#565a5c \#ff5a5f \#007a87}

Gambar 3. Pallet warna pada video animasi zat adiktif

\section{Typografi}

Font yang dipakai pada video animasi ini menggunakan dua font utama yaitu chunk five yang memiliki style retro dan arial round yang merupakan bagian dari san serif dan memiliki kesan soft. Font chunk five dipilih karena bila dilihat dari bentuk normalnya memiliki kesan tebal dan tegas sehingga cocok digunakan pada informasi penekanan, dan font arial round digunakan sebagi body text nya untuk mendeskripsikan informasi lebih jelas agar mudah dibaca dengan cepat,

\section{Leogline}

Peneliti merumuskan logline berdasarkan penggabungan referensi umum dan pengembangan ide, yang akan digunakan pada video animasi ini, yaitu "Bijak untuk tidak menggunakan Narkoba!! Katakan“TIDAK” untuk Narkoba!!" Logline ini dipilih karena untuk mewujudkan himbauan dan ajakan kepada penonton untuk tidak menggunakan jenis-jenis zat adiktif dan perilaku adiktif lainnya. 


\section{Ilustrasi}

Pada video animasi ini peneliti memilih ilustrasi aset grafis berbasis digital vector untuk menciptakan visualisasi kesederhanaan dengan konsep flat design. Hal ini ditujukan agar konten informasi baik teks maupun gambar didalam video dapat terlihat jelas dengan berbagai resolusi atau saat diperbesar.

\section{Gaya Visual Animasi}

Gaya visual yang digunakan dalam video animasi ini secara umum adalah flat design. Konsep visual flat design terlihat dari aset grafis yang digunakan, seperti karakter, property, tipografi, dan elemen-elemen pendukung lainnya. Konsep visual flat design pada video animasi ini lebih mengutamakan kesederhanaan, yaitu dengan tidak banyak menggunakan shadow, highlight, tekstur dan gradasi. Penyampaian informasi dan pesan juga dibuat dengan kata-kata yang sederhana dan mudah dipahami. Konsep kesederhanaan juga terlihat pada penggunaan font style yang mudah dibaca dan tidak terlalu rumit.

\subsection{Hasil Video Animasi}

Berikut preview akhir hasil perancangan video edukasi animasi 2D berbasis Motion Graphic. Setiap scene dilihatkan melalui screen shot preview pada tabel 1. sebagai berikut.

Tabel 1. Preview Video Animasi Zat Adiktif

\begin{tabular}{|c|c|c|c|}
\hline Scene & Visual & Text & Keterangan \\
\hline 1 & 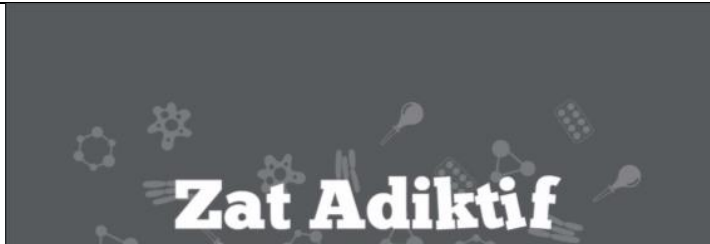 & $\begin{array}{l}\text { Opening Title } \\
\text { "Zat Adiktif" }\end{array}$ & $\begin{array}{l}\text { Action: - } \\
\text { Music: bensound- } \\
\text { inspire } \\
\text { Visual: Background } \\
\text { obat-obatan }\end{array}$ \\
\hline 2 & $\begin{array}{l}\text { Zat Adiktif adalah zat-zat } \\
\text { kimia yang terkandung } \\
\text { dalam obat-obatan. } \\
\text { Dapat menyebablan } \\
\text { ketergantungan "Adiksi" }\end{array}$ & $\begin{array}{l}\text { Text: } \\
\text { Zat adiktif adalah zat-zat } \\
\text { yang terkandung dalam } \\
\text { obat-obatan, } \\
\text { Dapat menyebabkan } \\
\text { ketergantungan "Adiksi" } \\
\text { bagi pemakainya. }\end{array}$ & $\begin{array}{l}\text { Action: karakter } \\
\text { utama bicara } \\
\text { Music: bensound- } \\
\text { inspire } \\
\text { Visual: } \\
\text { Karakter Utama }\end{array}$ \\
\hline 3 & $\begin{array}{l}\text { Zat Adiktif } \\
\text { dapat Merusak } \\
\text { Otak \& }\end{array}$ & $\begin{array}{l}\text { Text: } \\
\text { Zat adiktif dapat merusak.. } \\
\text { Otak \& Susunan Saraf }\end{array}$ & $\begin{array}{l}\text { Action: klasifikasi } \\
\text { dampak } \\
\text { Music: bensound- } \\
\text { inspire } \\
\text { Visual: } \\
\text { Gambar Otak }\end{array}$ \\
\hline
\end{tabular}




\begin{tabular}{|c|c|c|c|}
\hline 4 & $\begin{array}{l}\text { Zat Adiktif } \\
\text { dapat Merusak }\end{array}$ & $\begin{array}{l}\text { Text: } \\
\text { Zat adiktif dapat merusak. } \\
\text { Perilaku }\end{array}$ & $\begin{array}{l}\text { Action: klasifikasi } \\
\text { dampak } \\
\text { Music: bensound- } \\
\text { inspire } \\
\text { Visual: } \\
\text { Gambar Orang } \\
\text { Perilaku }\end{array}$ \\
\hline 5 & $\begin{array}{l}\text { Zat Adiktif } \\
\text { dapat Merusak }\end{array}$ & $\begin{array}{l}\text { Text: } \\
\text { Zat adiktif dapat merusak.. } \\
\text { Mood }\end{array}$ & $\begin{array}{l}\text { Action: klasifikasi } \\
\text { dampak } \\
\text { Music: bensound- } \\
\text { inspire } \\
\text { Visual: } \\
\text { Gambar orang dengan } \\
\text { mood }\end{array}$ \\
\hline 6 & $\begin{array}{l}\text { Narkoba... } \\
\text { Jenis obat yang termasuk } \\
\text { obat-obatan psikoaktif, Berdampak } \\
\text { pada perubahan jalan pikiran dan } \\
\text { susunan syaraf pusat seseorang. }\end{array}$ & $\begin{array}{l}\text { Text: } \\
\text { Jenis obat yang termasuk } \\
\text { obat-obatan psikoaktif, } \\
\text { Berdampak pada } \\
\text { perubahan jalan pikiran } \\
\text { dan susunan syaraf pusat } \\
\text { seseorang. }\end{array}$ & $\begin{array}{l}\text { Action: penjelasan } \\
\text { narkoba } \\
\text { Music: bensound- } \\
\text { inspire }\end{array}$ \\
\hline 7 & $\begin{array}{ll}\text { Wenurut } & \begin{array}{l}\text { Narkoba adalah sesuatu } \\
\text { yang dimasukkan kedalam } \\
\text { tubuh baik berupa zat yang } \\
\text { padat, cair, maupun gas } \\
\text { yang mengubah fungsi atau } \\
\text { struktur tubuh secara fisik } \\
\text { atau psikis. }\end{array} \\
\text { (1982) }\end{array}$ & $\begin{array}{l}\text { Text: Menurut WHO } \\
\text { (1982)Narkoba adalah } \\
\text { sesuatu yang dimasukkan } \\
\text { kedalam tubuh baik } \\
\text { berupa zat yang padat, cair, } \\
\text { maupun gas yang } \\
\text { mengubah fungsi atau } \\
\text { struktur tubuh secara fisik } \\
\text { atau psikhis. }\end{array}$ & $\begin{array}{l}\text { Action: penjelasan } \\
\text { narkoba } \\
\text { Music: bensound- } \\
\text { inspire }\end{array}$ \\
\hline 8 & Candu & $\begin{array}{ll}\text { Text: } \\
\text { Jenis Narkoba: } \\
- & \text { Coca } \\
- & \text { LSD } \\
- & \text { Candu } \\
- & \text { Ganja }\end{array}$ & $\begin{array}{l}\text { Action: Jenis narkoba } \\
\text { Music: bensound- } \\
\text { inspire } \\
\text { Visual: } \\
\text { Tanda Panah }\end{array}$ \\
\hline
\end{tabular}




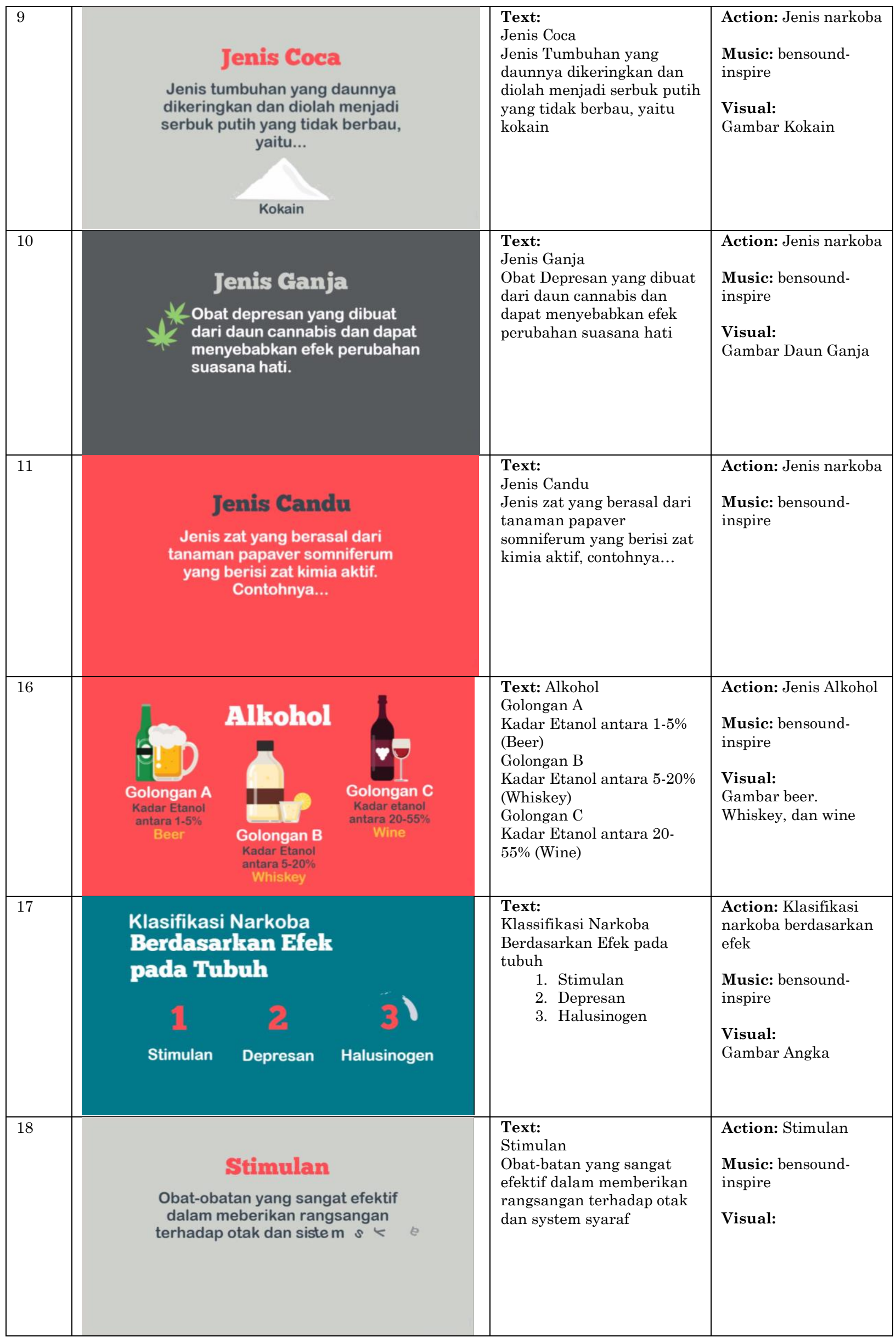




\begin{tabular}{|c|c|c|c|}
\hline 19 & $\begin{array}{l}\text { Stimulan } \\
1 \text { Menghambat perasaan lapar } \\
\text { Menurunkan perasaan letih } 2 \\
3 \text { Menurunkan kebutuhan tidur } \\
4 \text { Memicu kerja jantung } \\
\text { Meningkatkan tekanan darah } 5\end{array}$ & $\begin{array}{l}\text { Text:Stimulan } \\
\text { 1. Menghambat perasaan } \\
\text { lapar } \\
\text { 2. Menurunkan perasan } \\
\text { letih } \\
\text { 3. Menurunkan kebutuhan } \\
\text { tidur } \\
\text { 4. Memicu kerja jantung } \\
\text { 5. Meningkatkan tekanan } \\
\text { darah }\end{array}$ & $\begin{array}{l}\text { Action: Stimulan } \\
\text { Music: bensound- } \\
\text { inspire } \\
\text { Visual: }\end{array}$ \\
\hline 20 & Jenis & $\begin{array}{l}\text { Text: } \\
\text { Jenis Stimulan } \\
\text { Stimulan ringan (cafein) }\end{array}$ & $\begin{array}{l}\text { Action: Stimulan } \\
\text { Music: bensound- } \\
\text { inspire } \\
\text { Visual: } \\
\text { Gambar rokok, kopi, } \\
\text { the, dan coklat }\end{array}$ \\
\hline 23 & $\begin{array}{l}\text { Depresan } \\
\text { Obat-obatan yang dapat } \\
\text { mengakibatkan turunnya tingkat } \\
\text { kesadaran. Contoh... }\end{array}$ & $\begin{array}{l}\text { Text: } \\
\text { Depresan } \\
\text { Obat-obatan yang dapat } \\
\text { mengakibatkan turunnya } \\
\text { tingkat kesadaran. } \\
\text { Contoh... }\end{array}$ & $\begin{array}{l}\text { Action: Depresan } \\
\text { Music: bensound- } \\
\text { inspire } \\
\text { Visual: } \\
\text { Tanda Panah }\end{array}$ \\
\hline 24 & $\begin{array}{c}\text { Denghilangkan } \\
\text { rasa sakit }\end{array}$ & $\begin{array}{l}\text { Text: Deprensan Morfin } \\
\text { - Menghilangkan rasa } \\
\text { sakit } \\
\text { - Mengurangi rasa gelisah } \\
\text { - Memberikan rasa } \\
\text { gembira }\end{array}$ & $\begin{array}{l}\text { Action: Depresan } \\
\text { Music: bensound- } \\
\text { inspire } \\
\text { Visual: } \\
\text { Gambar ekspresi } \\
\text { sakit, ekspresi } \\
\text { gelisah, dan ekspresi } \\
\text { gembira }\end{array}$ \\
\hline
\end{tabular}

\subsection{Pendekatan Model Komunikasi SMCR dan Model Health Belief \\ 3.3.1 Pendekatan Health Belief Model}

Pada Scene 2 terdapat karakter utama animasi yang menjelaskan informasi tentang pengaruh zat adiktif pada seseorang, yang didukung dengan grafis perilaku seseorang. Komponen Health Belief Model yang digunakan adalah Perceived Susceptibility, yaitu kepercayaan seseorang tentang zat adiktif berbahaya, komponen ini juga didukung pada scene 3 , 4, dan 5 .

Selain ini ada juga pendekatan perceived Benefits yang disampaikan di akhir video pada scene 30, yaitu mengajak dan menghimbau penonton untuk tidak menggunakan narkoba. Perceived benefits adalah kepercayaan terhadap keuntungan dari metode yang disarankan untuk mengurangi resiko. Sehingga penonton sadar akan tidak menggunakan narkoba dan zat adiktif lainnya. Pendekatan ini diwakilkan dengan logline "Ayo Teman-teman, bijak untuk tidak menggunakan Narkoba ya!! Katakan "TIDAK" untuk Narkoba!!". Scene 28 menyadarkan penonton tentang bahayanya zat adiktif dengan didukung oleh scene 23, 24, 25, 26, dan 27.

\subsubsection{Pendekatan Model Komunikasi SMCR}

Video animasi ini menginformasikan secara terstruktur tentang apa itu zat adiktif, jenis dan klasifikasinya, dan dampak penggunaannya. Pada diagram Berlo, Consept art, animator, layout, 
graphic designer dipilih sebagai source. Message yang terkandung pada video ini adalah Informasi edukasi bahaya zat adiktif, pengertian singkat bahaya zat adiktif, jenis \& klasifikasi, dampak dan himbauangaya. Informasi disesuaikan dengan selera remaja. Channel yang digunakan adalah visual dan suara, yaitu pada indera mata dan telinga. Receiver disini adalah remaja, yang diharapkan dapat sadar akan bahaya zat adiktif, pengetahuan tentang jenis dan klasifikasi zat adiktif brtambah, dan mengantisifasi terhadap zat-zat adiktif dan perilaku adiktif berbahaya.

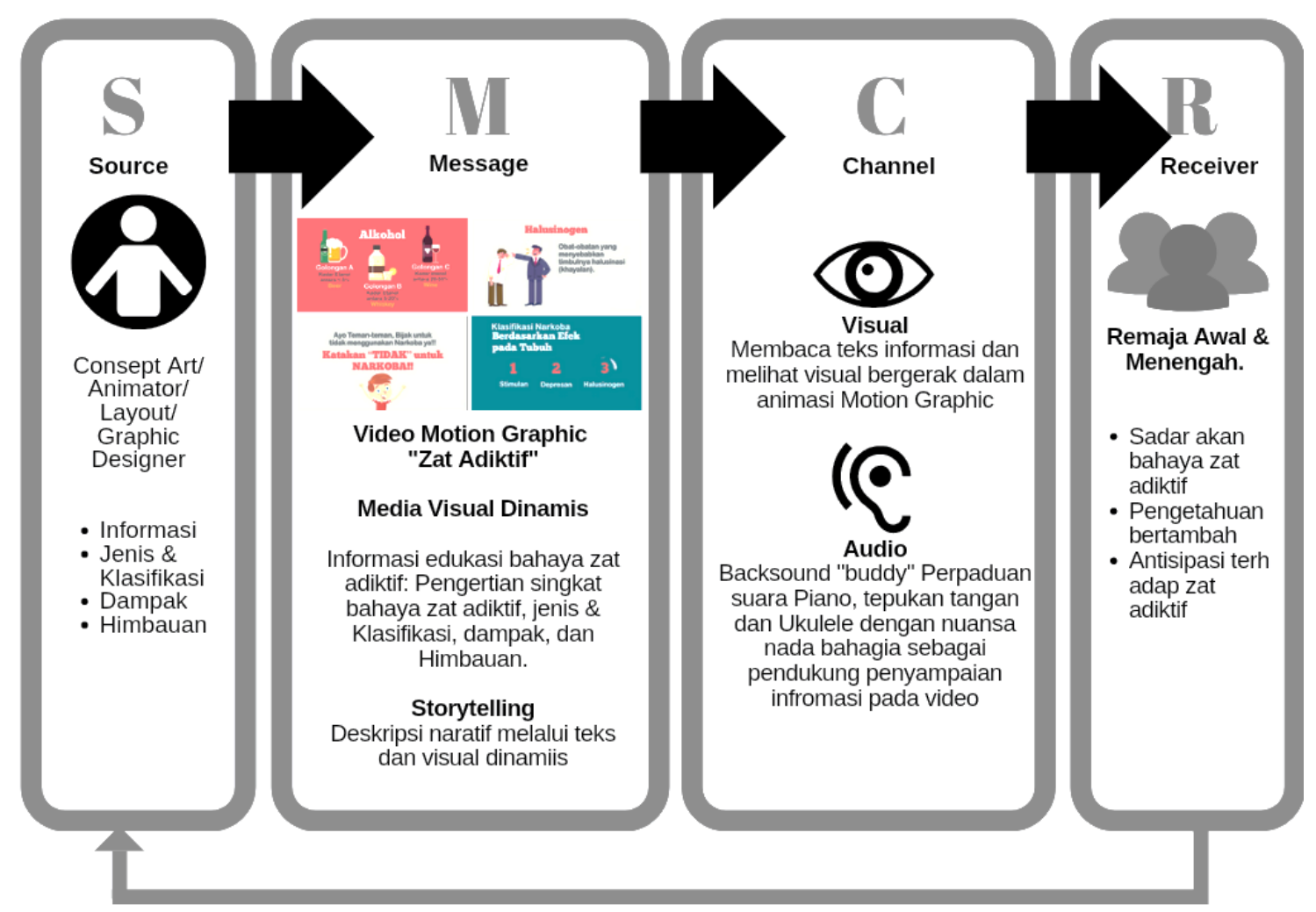

Gambar 4. Pendekatan Model Komunikai Berlo pada video animasi zat adiktif

\section{Kesimpulan}

Pendekatan model komunikasi Berlo (model SMCR) dipilih agar Message yang disampaikan dapat diterima tepat pada Receiver (Remaja), yaitu informasi dikemas dengan bahasa dan visual yang sederhana, serta audio yang dipilih disesuaikan dengan selera remaja. Peneliti juga mengadaptasikan Health Belief Model dengan menggunakan kata-kata himbauan dan ajakan untuk tidak bersifat adiktif. Penyampaian informasi edukasi tentang bahaya zat adiktif yang ditujukan pada remaja yang disampaikan melalui video animasi $2 \mathrm{D}$ berbasis motion graphic, agar informasi dapat lebih diterima dan dipahami oleh reamaja. Pengetahuan dan pemahaman yang rinci dan terstruktur tentang bahaya zat adiktif perlu diberikan kepada remaja untuk menghindari terjerumus perilaku menyimpang. Dengan adanya pemanfaatan video animasi motion graphic ini yang merupakan media komunikasi visual yang dapat memberikan pengemasan informasi menjadi lebih menarik. Motion graphic selain berfungsi menarik perhatian penonton, juga bertujuan untuk memperjelaskan pesan informasi yang disampaikan, Selain itu penonton lebih mudah mengingat konsep dan gagasannya sehingga penonton termotivasi untuk melihat dan memahami informasi pada video. 


\section{Daftar Pustaka}

1. Esti Kurniawati, Dyah dkk. 2010. Gambaran Skrining Keterlibatan Penggunaan Alkohol, Rokok, dan Zat Adiktif pada Mahasiswa D3 Fakultasa Teknik Universitas Gadjah Mada. Berita Kedokteran Masyarakat, Vol. 26, No. 2. Diambil dari: https://journal.ugm.ac.id

2. Green, E. C., \& Murphy, E. 2014. Health belief model. The Wiley Blackwell encyclopedia of health, illness, behavior, and society.

3. Munir, Prof. Dr. 2012. Multimedia: Konsep \& Aplikasi Dalam Pendidikan. Jakarta: Alfabeta

4. Soenyoto, Partono. 2017. Animasi 2D. PT Elex Media Komputindo. Jakarta.

5. Yusa, I. M. M., \& Saputra, I. P. S. 2016. Pemanfaatan Animasi 2 Dimensi Model Infografik dalam Perancangan Video Iklan Layanan Masyarakat Tentang Pengolahan Sampah Rumah Tangga di Denpasar. Jurnal Nasional Pendidikan Teknik Informatika (Janapati), 5(1), 1-10.

6. Nasution, Yusran dkk. 2003. Tingkat Pengetahuan Orang Tua Murid SLTP tentang Narkotika, Alkohol dan Zat Adiktif Lainnya di Kotamadya Depok Tahun 2002. MAKARA, KESEHATAN, VOL. 7, NO. 1. Diambil dari: http://repository.ui.ac.id/dokumen/lihat/51.pdf

7. Laporan Kinerja Dit. Pengawasan Narkotika, Psikotropika, dan Zat Adiktif. Optimization Online, https://www.pom.go.id on Juni 25, 2019. 